\title{
Who are the students who take precalculus?
}

\author{
Mercedes A. McGowen \\ William Rainey Harper College \\ Palatine, IL 60067-7398 \\ email: mmcgowen@harper.cc.il.us
}

\begin{abstract}
This paper examines the questions: Who are the undergraduate students who enroll in precalculus courses? What courses do students take after completing a precalculus course? These questions are addressed by an analysis of enrollment in mathematics courses at two- and four-year colleges and at universities over the past twenty years, followed by a demographic profile of students at a midwestern twoyear college whose mathematics course enrollment closely parallels enrollment at two-year colleges nationally. ${ }^{1}$
\end{abstract}

\section{What is "precalculus"?}

As we begin the task of rethinking the precalculus curriculum, we first need to examine our assumptions about precalculus. Do we, as well as members of our own departments, colleagues in other institutions, and those teaching in the high schools mean the same thing when we characterize a course or courses as "precalculus"? Colleagues asked what "precalculus" is, gave the following responses:

- the courses before calculus (College Algebra, Trigonometry, and Precalculus/Elementary Functions, and Modeling).

- a specific course which combines college algebra (including the topics of induction, theory of equations, sequences, and series) and trigonometry.

- 2nd year high school algebra and a brief introduction to trigonometry.

- a high school algebra and trigonometry course for students in the accelerated track.

Answers to the question: What is "college algebra"? also vary. Some respond that it is third algebra course taken in high school-a one-semester course taken after Algebra I and Algebra II have been completed. Others believe it is the second year of high school algebra renamed because it is taken in college by under prepared undergraduates. As Humpty Dumpty pointed out to Alice in Through the Looking Glass: "You see, it's like a portmanteau-there are two meanings packed

1. The author wishes to thank David Lutzer and Stephen Rodi for providing the 2000 CMBS statistical survey data (in press) which are cited in this paper. 
up into one word." In this instance, there are more than two meanings. Clarification of the terms "precalculus" and "college algebra" is needed if we are to answer the questions: What is precalculus? Which students take precalculus? What courses do they take after completing a precalculus course? In this paper, the term precalculus refers to those courses intended to prepare students to take Calculus: College Algebra, Trigonometry, the combined College Algebra/Trigonometry course or a Precalculus/Elementary Functions course.

\section{What mathematics courses do undergraduate students enroll in?}

Sixty-eight percent of incoming freshman at four-year colleges and universities took four years of mathematics in high school in 1997 [National Center for Education Statistics, 1997]. In Fall, 2000, more than three million students attending two- and four-year colleges and universities were enrolled in mathematics courses taught in departments of mathematics/mathematical sciences. However, many who complete three or four years of "rigorous" high school mathematics are unsuccessful in subsequent college-level mathematics courses. Twenty-two percent of the three million students $(653,000)$ were enrolled in precalculus courses-courses many had previously completed in high school. As undergraduates, students often find themselves repeating their high school courses, receiving no general education credit in college for these courses. Explanations given include (a) students didn't retain what they learned in high school; (b) the algebraic competencies and understandings were insufficient foundation for success subsequently; (c) the college placement exam inappropriately placed students. Whatever the reason(s), it appears that precalculus courses are yet another effective filter—not a pump—-for many students.

There are no national studies which provide answers to the questions:

- Who are the students who take precalculus as undergraduates?

- Why do they take precalculus?

- How appropriately is the present precalculus curriculum aligned with the needs of students who enroll in these courses?

- What do other programs want students to know upon completion of precalculus courses? 
How many of the students who enroll in precalculus courses intend to enroll in calculus? There is a growing consensus that the precalculus courses currently offered are not meeting the needs of those intending to major in mathematics or for others who need math-intensive programs. Many seriously question whether the precalculus courses currently offered are the appropriate prerequisite for students in non-mathematics intensive programs. They are interested in knowing how many students take a precalculus class solely because the course is a required prerequisite for their particular program of study which does not require any additional mathematicsintensive coursework. How many of the students who take precalculus courses are successful in subsequent mathematics courses - assuming they take another mathematics course-remains an open question.

\section{Mathematics Course enrollment: 1980-2000}

Mathematics course enrollments taught in departments of mathematics at colleges and universities have increased $18 \%$ since 1980. Most of that growth occurred at two-year colleges where mathematics enrollment increased $41 \%$ during the past twenty years-eight times the $5 \%$ increase at four-year colleges and universities. In Fall, 2000, 44\% of all undergraduates enrolled in mathematics courses attended two-year colleges.

\section{FIGURE 1. Total Mathematics enrollment \& Total Remedial enrollment (in thousands)}
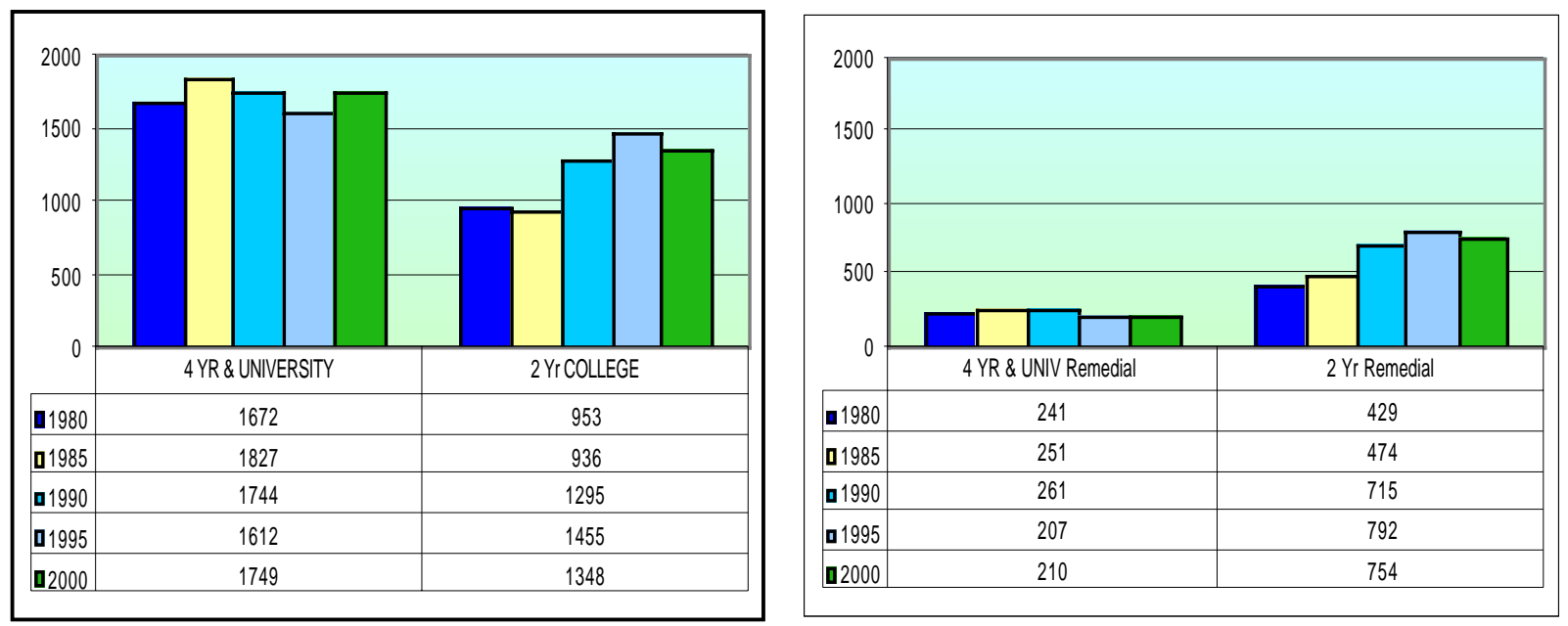

Data Source: CBMS Statistical Abstract (2000 draft) Table A-1 and Table TYR.3. 
The growth in enrollment at two-year colleges has included increasing numbers of students who begin college taking remedial courses. Enrollment in these courses has skyrocketed since 1980-increasing 76\%. In Fall, 2000, remedial course enrollment constituted 12\% of the total mathematics course enrollment at four-year colleges and universities and 56\% of total mathematics course enrollment at two year colleges.

Non-remedial mathematics courses also experienced increased enrollment over the past twenty years at four-year colleges and universities, as well as two-year colleges. It is of interest to note in which courses increases in enrollment occurred. Our particular interest is in the precalculus course enrollment. Since preparation for calculus is the goal of precalculus and significant efforts have gone into reforming both the curriculum and instructional approaches utilized in mainstream calculus courses-let us examine the national calculus enrollment data and the effect of calculus curriculum initiatives on mathematics enrollment during the past decade before turning our attention to the precalculus enrollment data.

The Tulane Conference in 1986 reaffirmed the importance of calculus in the curriculum and had as its purpose the development of alternative curricular materials and instructional strategies, with the goal of transforming calculus from a filter into a pump [Douglas, 1986]. Building on that initiative, various changes have been introduced into the mainstream calculus curriculum during the past ten years [CBMS 2000 draft, Table SFY.19; 1995, SFY.19]. At four-year colleges and universities:

- Use of graphing calculators in mainstream Calculus I classes has grown from 3\% in 1990 to $47 \%$ in 2000 .

- Computer assignments were required in $9 \%$ of these classes in 1990. By 2000,31\% of the Calculus I classes included computer assignments.

- Group projects and writing assignments were regular features in 5\% of these courses in 1990. Ten years later, 27\% of Calculus I classes include writing assignments and 19\% include group projects.

Two year colleges have seen similar reform initiatives incorporated into the Calculus I curriculum. 
- Graphing calculators are now used in $78 \%$ of the classes and $35 \%$ include computer assignments.

- Twenty-seven percent of classes currently assign group projects and $31 \%$ include a writing component.

What effect have the changes introduced into the calculus curriculum had on enrollment? Despite ongoing efforts to transform calculus from a filter into a pump with implementation of various reform initiatives during the past fourteen years-the actual number of students enrolled in main-stream calculus courses declined more than 12\% since 1985- the year before the Tulane Conference. Comparing the percent of students enrolled in Calculus of the total number enrolled in mathematics courses in 1980 with the percent enrolled in Calculus in 2000 reveals an even more discouraging story - the percent of students enrolled in mainstream calculus courses also declined. In 1980, 405,000 students were enrolled in calculus courses at four-year colleges and universities-24\% of the total mathematics enrollment. As of Fall, 2000, calculus enrollment had dropped to 352,000 students $-20 \%$ of the overall Fall, 2000 mathematics course enrollment. Mainstream calculus enrollment at two-year colleges also declined-from $8 \%$ of the total mathematics enrollment in 1980 to $6 \%$ in 2000.

\section{FIGURE 2. Calculus enrollment compared to Total Mathematics enrollment (in thousands)}

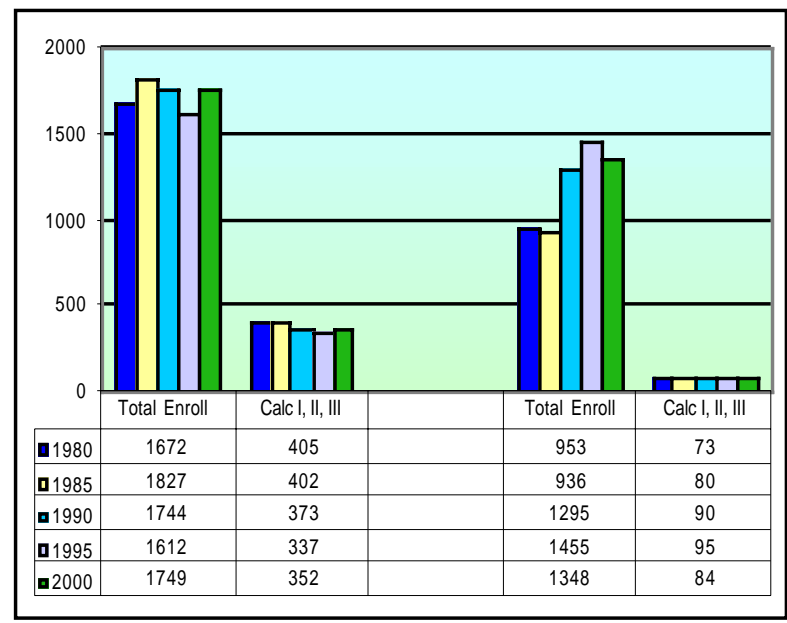

4 YR \& Univ

2 YR

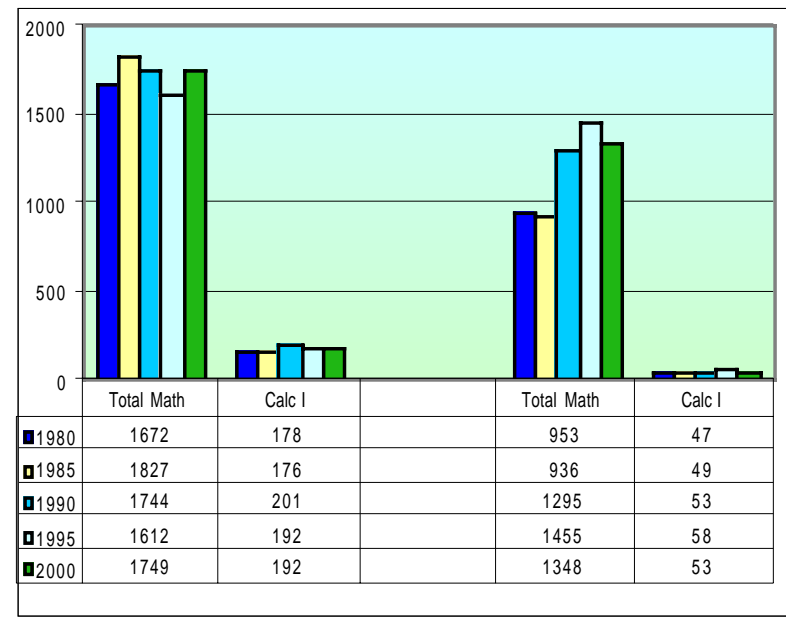

4 YR \& Univ
2 YR

Data Source: CBMS Statistical Abstract (2000 draft) Table A-1 and Table TYR.3. 
Calculus I enrollment has remained relatively constant since 1980, varying between $11 \%$ of the total number enrolled in mathematics courses that year to a high of $12 \%$ in 1995 , falling back to $11 \%$ in Fall, 2000. Two-year college Calculus I enrollment has also remained constant at $4 \%$ of the total mathematics enrollment over the past twenty years.

Non-mainstream calculus enrollment has also shrunk since 1990, decreasing $29 \%$ from a high of 163,000 in 1990 to 115,000 in 2000 . Two-year college non-mainstream calculus courses experienced an even greater loss of enrollment. In 1990, two-year enrollment peaked at 31,000. Ten years later, only 16,000 students were enrolled in non-mainstream calculus courses-a $48 \%$ decrease.

Given that the total number of undergraduates taking mathematics courses has increased $18 \%$ while mainstream and non-mainstream calculus enrollments declined-and the number of students in Calculus I remained relatively constant over the past twenty years-What mathematics courses are students taking? The answer is: non-calculus based mathematics courses.

FIGURE 3. Enrollment in calculus vs. non-calculus based courses (in thousands)

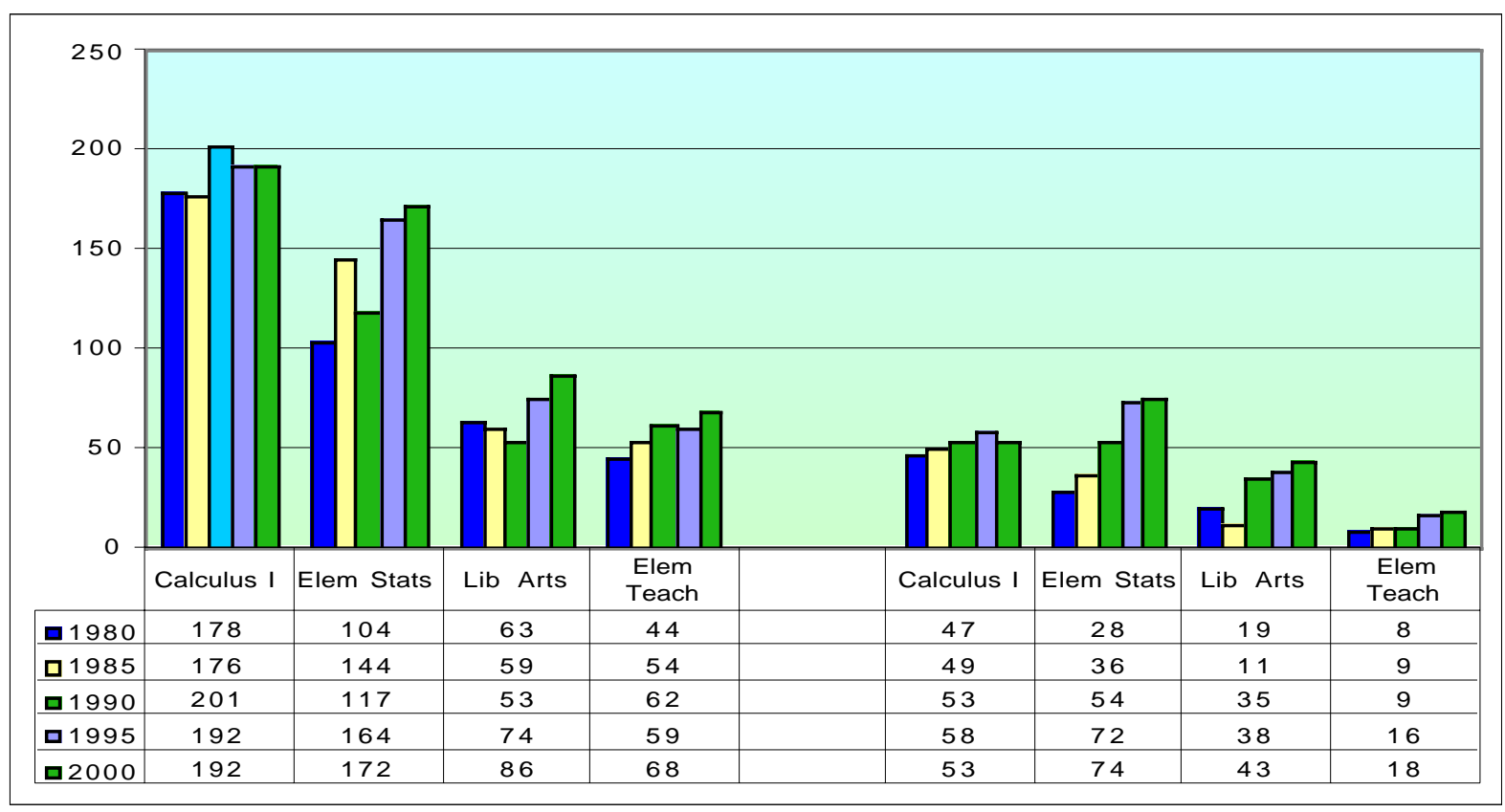

4 YR Colleges \& Universities

2 YR. Colleges

Data Source: CBMS Statistical Abstract (2000 draft) Table A-1 and Table TYR.3. 
As of Fall 2000, the CBMS data indicate that:

- Elementary statistics courses enrollment increased sixty-five percent.

- Content course(s) enrollment for elementary teachers increased fifty-five percent.

- Liberal arts mathematics course enrollment increased thirty-seven percent.

Enrollment in elementary statistics courses is approaching the Calculus I enrollment at four-year colleges and universities. The growth in two-year college enrollment of the non-calculus based courses is even greater than that in the four-year colleges and universities. Non-calculus-based elementary statistics course enrollment grew by $164 \%$ and now exceeds enrollment in Calculus I. The liberal arts and the math content courses for elementary teachers enrollments have more than doubled during the past twenty years.

\section{Precalculus Enrollment: 1980-2000}

Since 1980, enrollment in the various precalculus courses increased $17 \%$ at four-year colleges and universities. During the past decade, enrollment increased in all precalculus courses except Trigonometry, which declined 11\%. Since 1990 enrollment in the Precalculus/Elementary Functions course increased $46 \%$, more than eleven times the growth in enrollment in College Algebra. Despite a much smaller increase of $4 \%$ growth during the past ten years, College Algebra enrollment is more than double the Precalculus/ Elementary Functions course enrollment. Combined College Algebra/Trigonometry course enrollment experienced a $6 \%$ increase during this time.

Two-year college precalculus enrollment reveals a similar picture over the past ten years. College Algebra experienced a $13 \%$ increase-more than three times the increase in the course at four-year colleges and universities-remaining the course with the greatest enrollment. The Precalculus/Elementary Functions course, like its counterpart at four-year colleges and universities, experienced the greatest growth, increasing 37\%. Both Trigonometry and the combined College algebra/Trigonometry enrollment at two-year colleges declined-23\% in Trigonometry and $11 \%$ in the combined course. 
The increasing enrollment in the Precalculus/Elementary Functions course could be interpreted as an attempt to strengthen the preparation of students intending to take Calculus by directing students who indicate their intent to pursue a mathematics-intensive program into a more rigorous course-recognizing that the College Algebra course includes large numbers of students who are not intending to take Calculus subsequently.

\section{FIGURE 4. enrollment in precalculus courses (in thousands)}

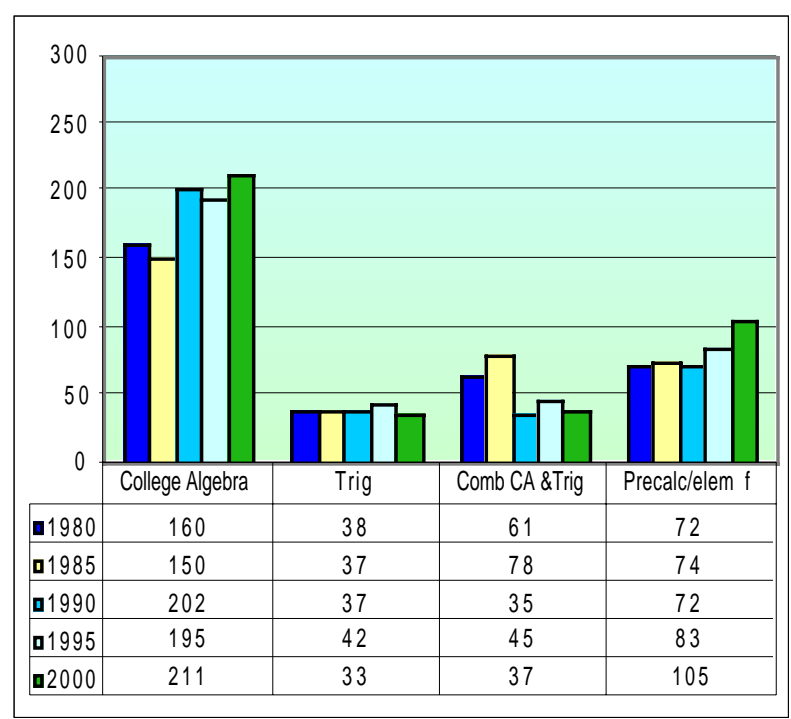

4 YR \& University

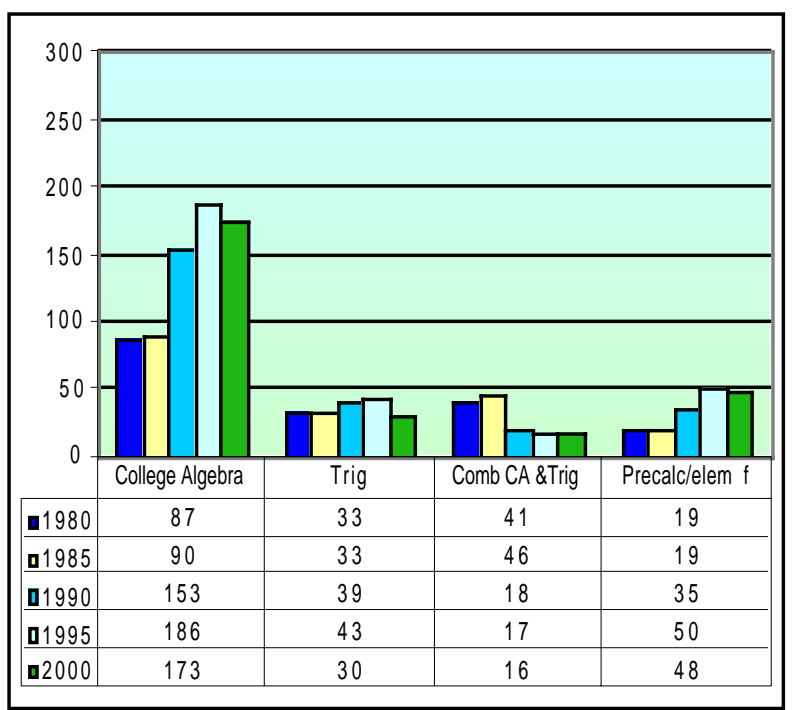

2 YR College

Data Source: CBMS Statistical Abstract (2000 draft) Tables A-1 and TYR.3.

A comparison of enrollment for precalculus courses and Calculus I over the past twenty years reveals that the increasing precalculus enrollment has had little, if any, impact on the Calculus I enrollment. Between 1980 and 1990, total calculus enrollment exceeded the precalculus enrollment at four-year colleges and universities. During that ten-year period, calculus enrollment declined, precalculus enrollment increased, and, since 1995, the precalculus enrollment has exceeded the 4-year college and university calculus enrollment.

A comparison of precalculus and Calculus enrollment at two-year colleges documents an even sharper contrast of growth in precalculus enrollment and the lack of growth in calculus enrollment. 
FIGURE 5. A comparison of Calculus and precalculus enrollment (in thousands)

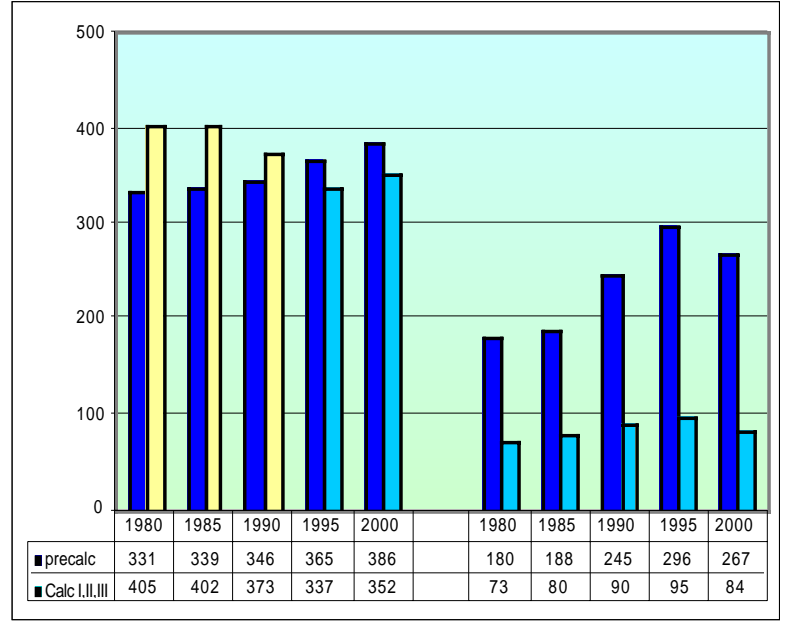

4 YR. \& Univ

2 YR. College

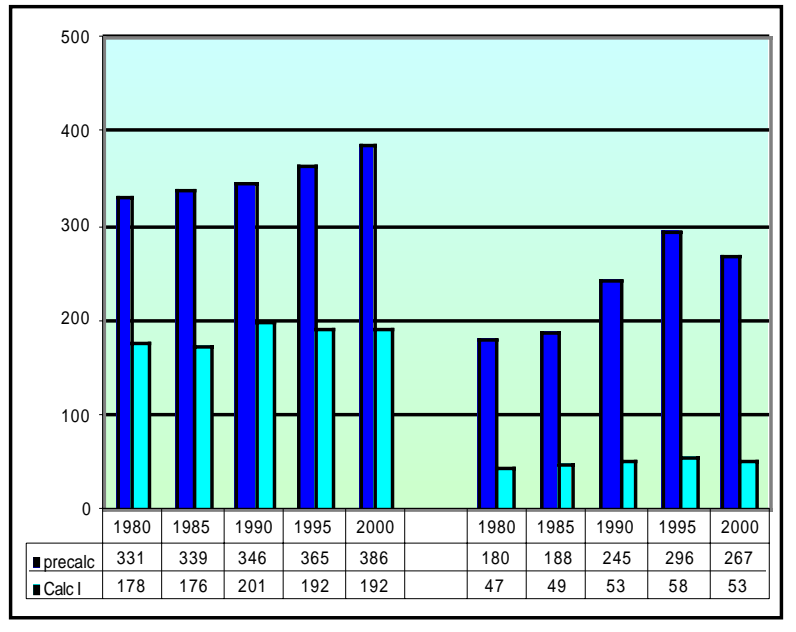

4 YR. \& Univ
2 YR. College

Data Source: CBMS Statistical Abstract (2000 draft) Table A-1 and TYR.3.

If we disaggregate the data by type of institution, we note that mainstream calculus enrollment exceeded precalculus enrollment in 1995 and 2000 only at Ph.D. institutions. At M.A., B.A. and two-year colleges, precalculus enrollment exceeded mainstream calculus enrollment, with the gap between precalculus and Calculus I enrollment widening over the past five years.

\section{FIGURE 6. Calculus and precalculus enrollment by type of institution (in thousands)}

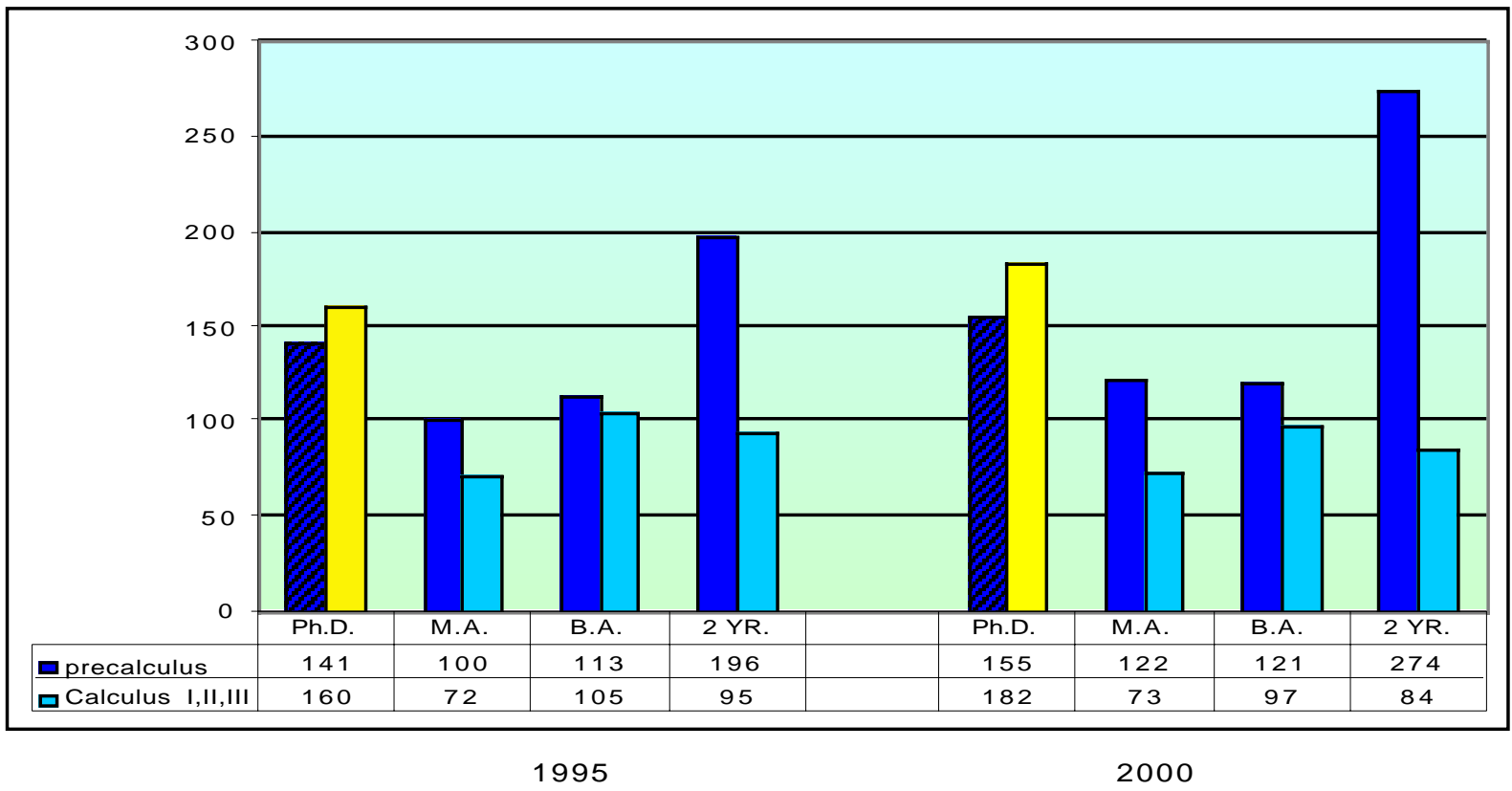

Data Source: CBMS Statistical Abstract (2000 draft) Table A-1; (1995), Table A-1, pp. $128-128$. 
A comparison of Calculus I enrollment with precalculus enrollment in 1995 and 2000 shows that precalculus enrollment exceeds Calculus I enrollment at all types of institutions.

FIGURE 7. Calculus I and precalculus enrollment by type of institution (in thousands)

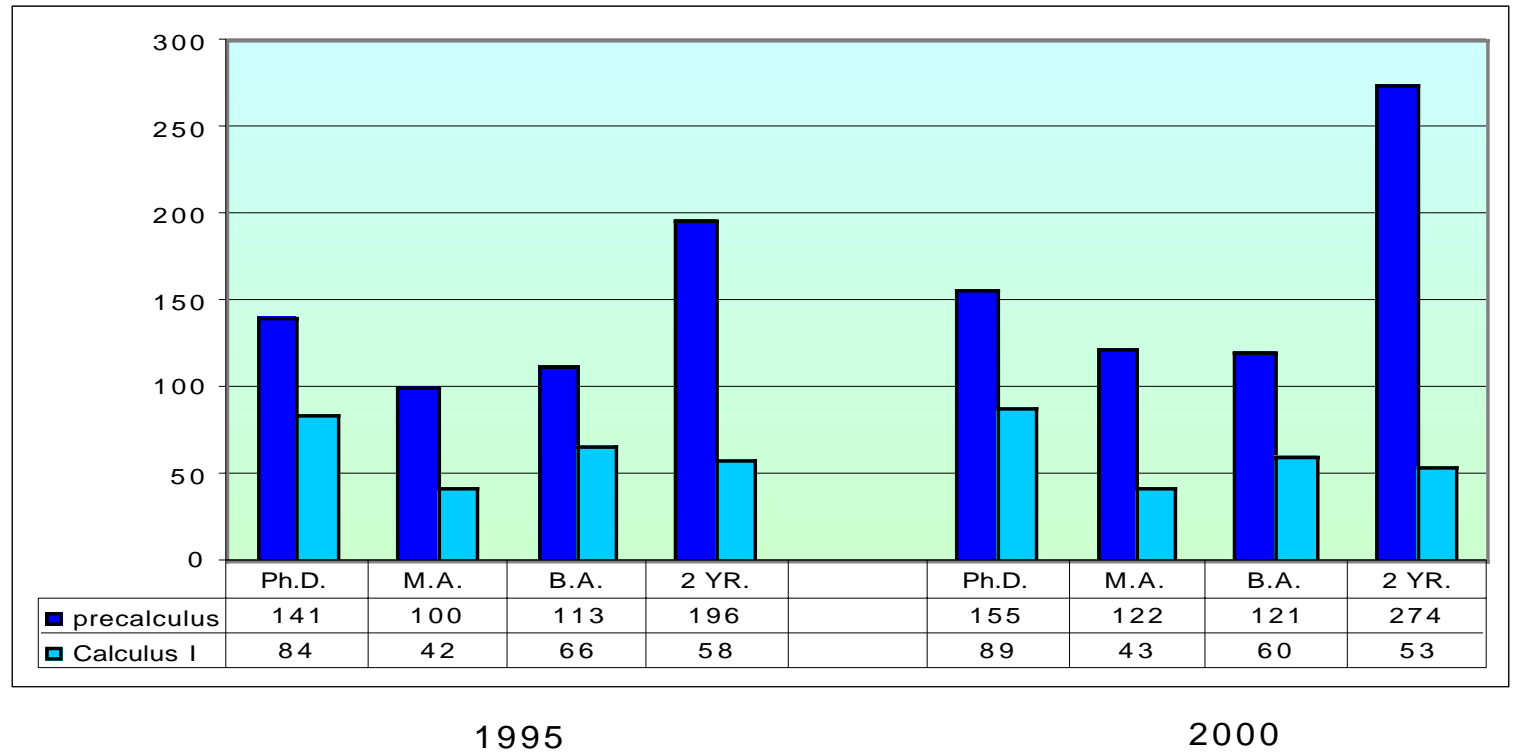

Data Source: CBMS Statistical Abstract (2000 draft) Table A-1; (1995), Table A-1, pp. 128-128.

\section{Meeting the needs of our students: A Two-Year College Profile}

An examination of national enrollment data suggests that the present precalculus curriculum does not meet the needs of many of the students enrolled in precalculus courses-those who enroll in precalculus courses intending to take calculus, as well as those who take a precalculus class only because the course is a required prerequisite for their program of study. It appears that large numbers of students do not have learning experiences in the precalculus courses which generate enthusiasm and subsequent enrollment in Calculus I and a program of studies in mathematics or other math-intensive fields.

Aggregate data summarize various quantifiable factors and indicate trends. They do not tell the whole story. Individual institutions also have stories to tell—stories that confirm the national profile and stories that contradict or modify the national profile. We all know of institutions which have introduced new curriculum materials and incorporated changes in their instructional strategies. We cite the successes and failures of these efforts to transform the curriculum. Each story 
provides information which can be utilized to make informed decisions and contributes to our understanding of who takes precalculus. We now consider the story of one midwestern community college and the efforts of the mathematics faculty at that institution to address some of the questions raised in this paper.

During Spring, 1998, the Department of Mathematical Sciences at William Rainey Harper College began a large-scale project to improve the effectiveness of the mathematics curriculum. The goal was to assess, revise, and restructure the curriculum to meet the needs of students for the 21 st century and the needs of the various disciplines served by the Department. One of the first tasks was to collect demographic information, enrollment data, and longitudinal data on student success in subsequent courses to determine how well each course is presently meeting its goals and objectives. Harper College Foundation grants provided funds for reassigned time for full-time faculty and stipends for adjunct faculty members to work on the project.

A demographic survey was administered twice in all mathematics courses-during Spring $1999(n=2286)$ and Fall $1999(n=1609)$ semesters. The survey responses indicate that:

- nearly $90 \%$ of students enrolled in mathematics courses plan to transfer to four-year colleges or universities.

- the vast majority of students enrolled in mathematics courses are white, non-hispanic (76\%), with Asian/Pacific islanders as the second largest ethnic group(13\%), followed by Hispanics (8\%).

- seventy-one percent of students enrolled in mathematics courses at Harper were full-time students (12 credit hours or more) in the Fall semester (63\% were full-time during Spring semester).

- the numbers of male and female students were approximately equal.

- approximately $15 \%$ of Harper's students were enrolled in math-intensive courses.

- more than $60 \%$ of all students were enrolled in mathematics courses which do not satisfy state undergraduate general education requirements for graduation (remedial courses, College Algebra, Trigonometry).

Harper College course enrollment approximates the national enrollment pattern of two-year colleges. Harper has a smaller percent of total mathematics enrollments in remedial mathematics 
and a larger percent of students in Calculus I than do two-year colleges nationally. Enrollment in Elementary Statistics increased 28\% since 1998-well below the increase nationally.

\section{FIGURE 8. Two-year \& Harper College enrollment as percents of total math enrollment}

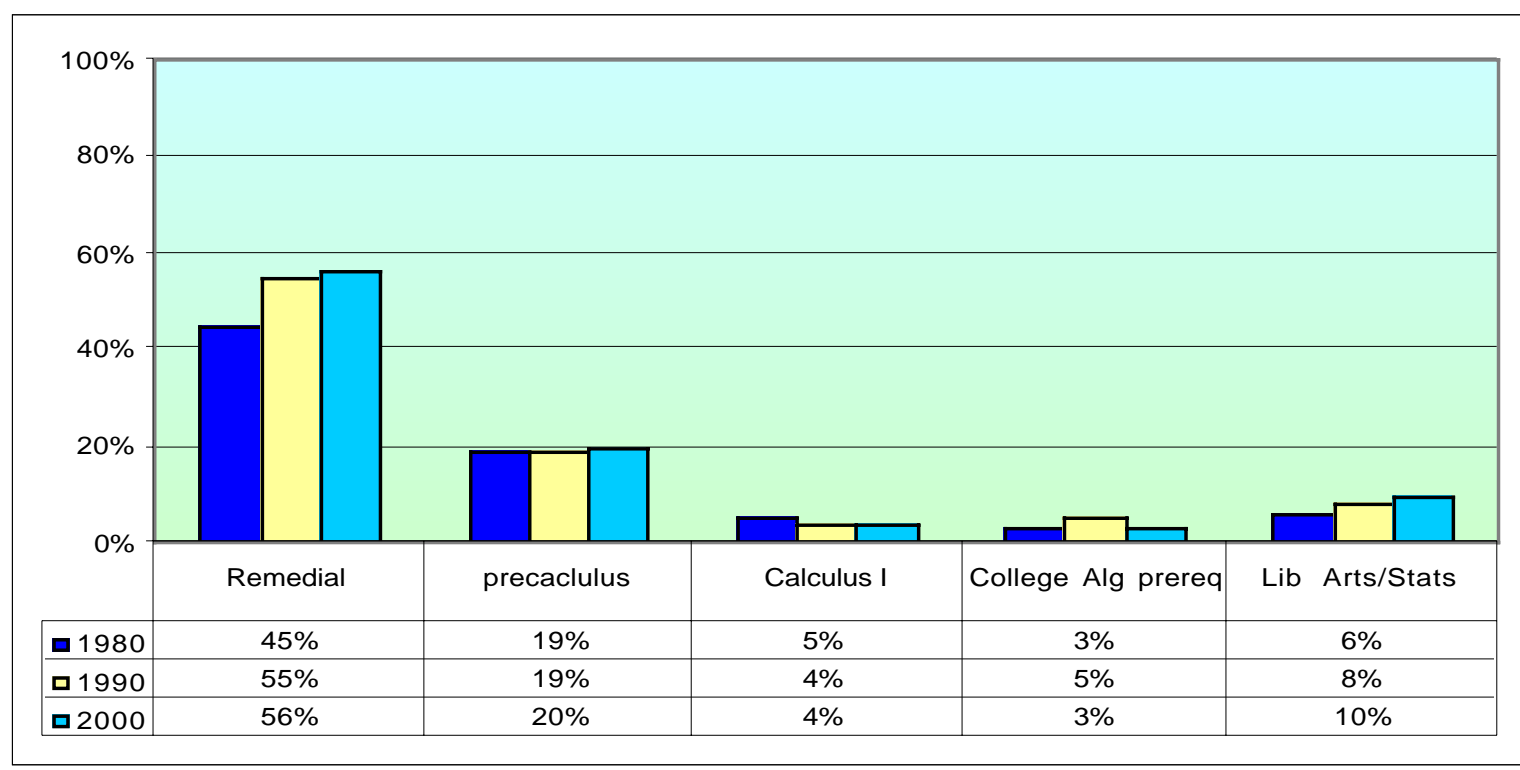

Two-Year Colleges: 1980, 1990, 2000

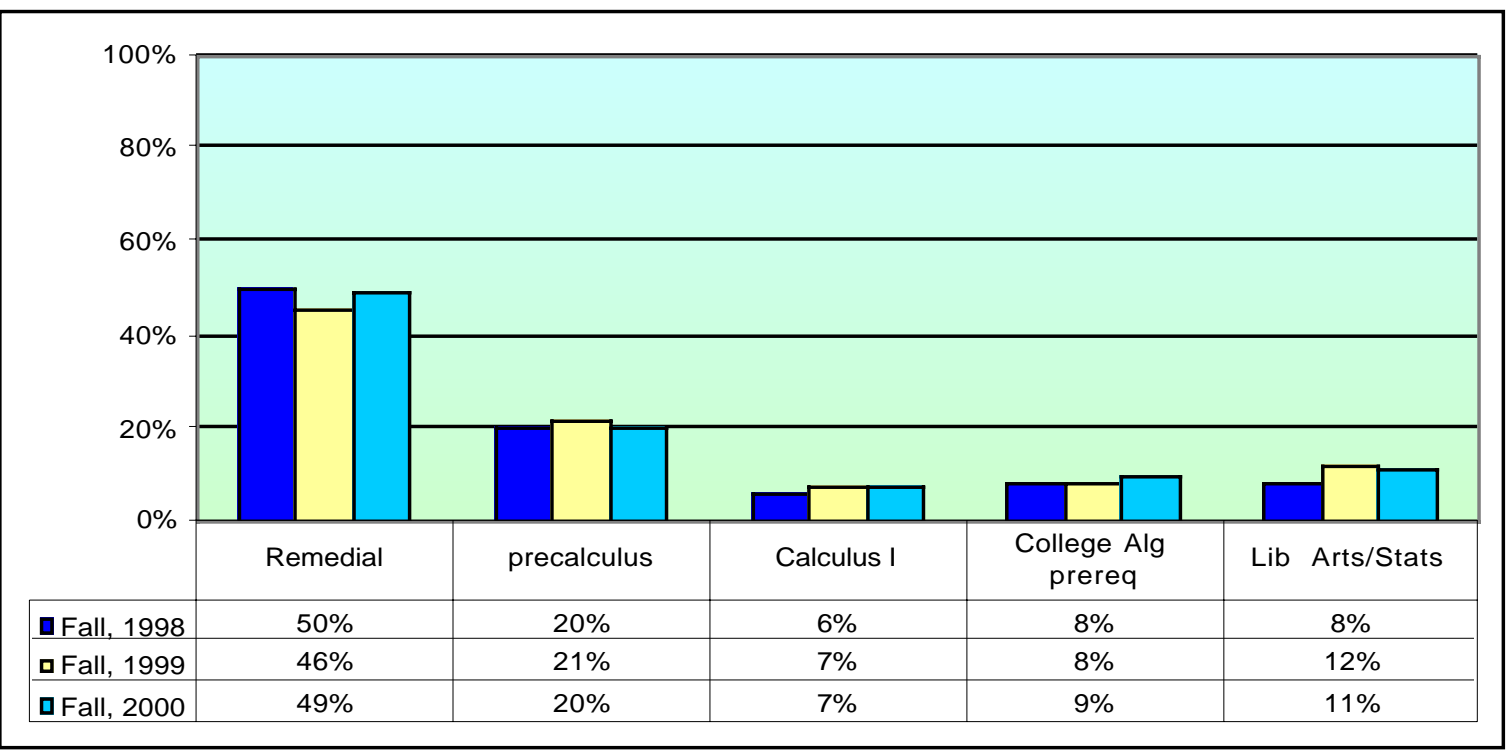

Harper College: 1998, 1999, 2000

Data Source: Harper Institutional Research(2001).

The percent of Harper students who take precalculus courses is the same as the percent enrolled nationally. Both precalculus and calculus enrollments at Harper have remained relatively constant over the three years we have been collecting data. Though the precalculus enrollment 
constitutes $20 \%$ of Harper's total mathematics enrollment, only $11 \%$ of students who take mathematics courses at Harper were enrolled in Calculus I each of the past three years. The combined Calculus I and II enrollment at Harper was one and one-half times the national average for twoyear colleges. Students at Harper, like their counterparts at other two- and four-year colleges and universities, enroll in College Algebra in far greater numbers than in Calculus I. The number of students enrolled in College Algebra over the past three years was three times the number of students who took Calculus I.

FIGURE 9. Harper College Calculus \& Prerequisite enrollment: 1998, 1999, 2000 (actual)

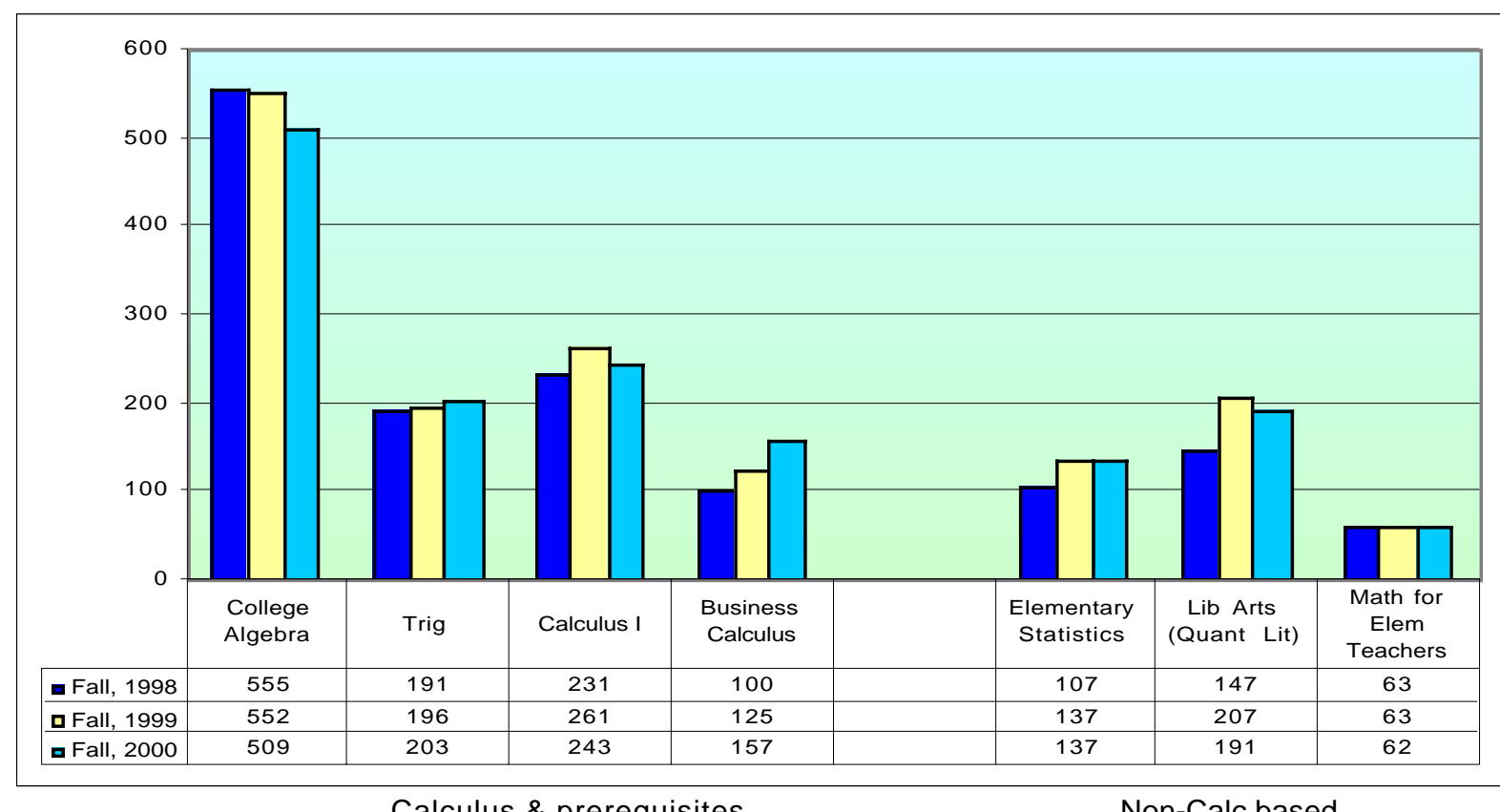

Calculus \& prerequisites

Non-Calc based

Data Source: Harper Institutional Research (2001).

Faculty most often cite students' lack of knowledge of trigonometry and their inability to interpret and make sense of their responses as greater problems than the lack of algebraic skills, which are often quite proficient. The data reveal that many Calculus I students are not coming from the precalculus course(s). Where do the Calculus I students come from? The department analyzed data on enrollment and success based on method of placement, hoping to answer this question. 
At Harper three different methods of placement are used: a student's ACT or SAT score; COMPASS (a computer-generated placement test developed by ACT); or successful completion of the prerequisite course at Harper (a grade of $\mathrm{C}$ or better). The COMPASS exam is the means by which most students are placed into developmental courses. Successful completion of Intermediate Algebra is the prerequisite for students who enroll in the precalculus courses, College Algebra and Trigonometry which are prerequisite for Calculus I. Since 1998, 54\% of all students enrolled in precalculus courses also took the prerequisite course, Intermediate Algebra, at Harper. The number of students who placed into Calculus I via ACT/SAT score or COMPASS exceeded the number who entered via Harper's precalculus courses.

Precalculus courses continue to be major stumbling blocks for many students at Harper. Since 1998, more than twenty-two hundred students enrolled in precalculus courses-yet fewer than one-third of the 1086 students who successfully completed the precalculus course(s) enrolled in Calculus I.

FIGURE 10. Harper College: Percent of Course via Placement \& Success via Placement

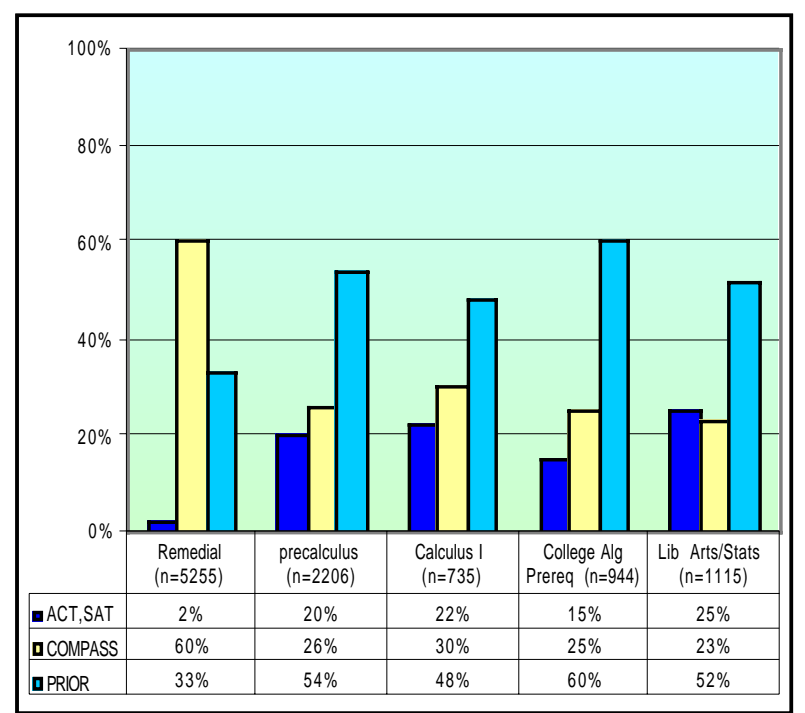

Percent of Course via Method of Placement

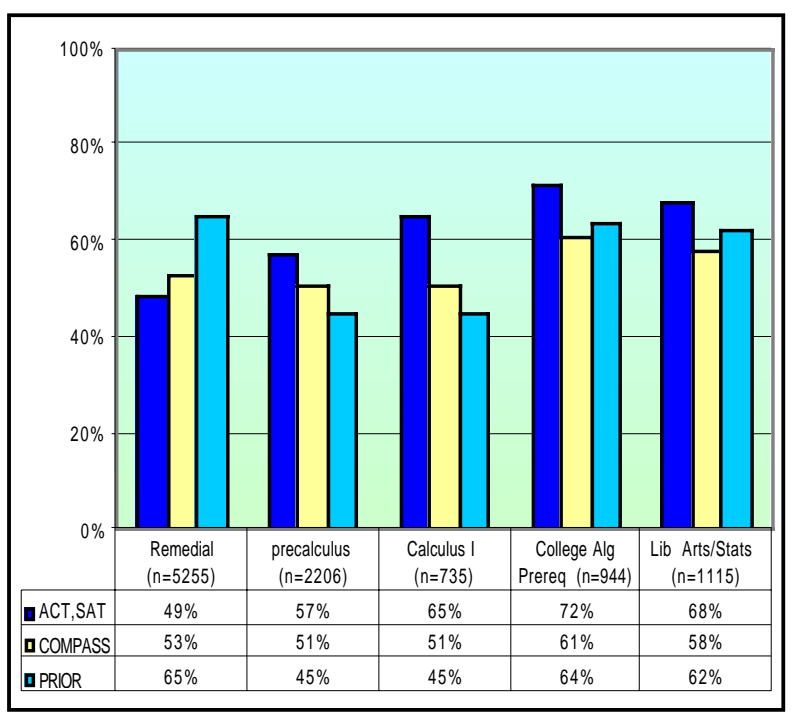

Success in Course via Method of Placement

Data Source: Harper Institutional Research (2001).

A student's ACT (or SAT) score has been the most accurate predictor of success in precalculus, Calculus I, and courses which have College Algebra as the prerequisite, i.e., Finite Mathemat- 
ics and Business Calculus; as well as the mathematics courses generally taken by liberal arts majors-Elementary Statistics (non-calculus based), Quantitative Literacy, and the Mathematics Content Courses for Elementary Teachers.

FIGURE 11. Comparison of Enrollment \& Success via Method of Placement 1998-2000.

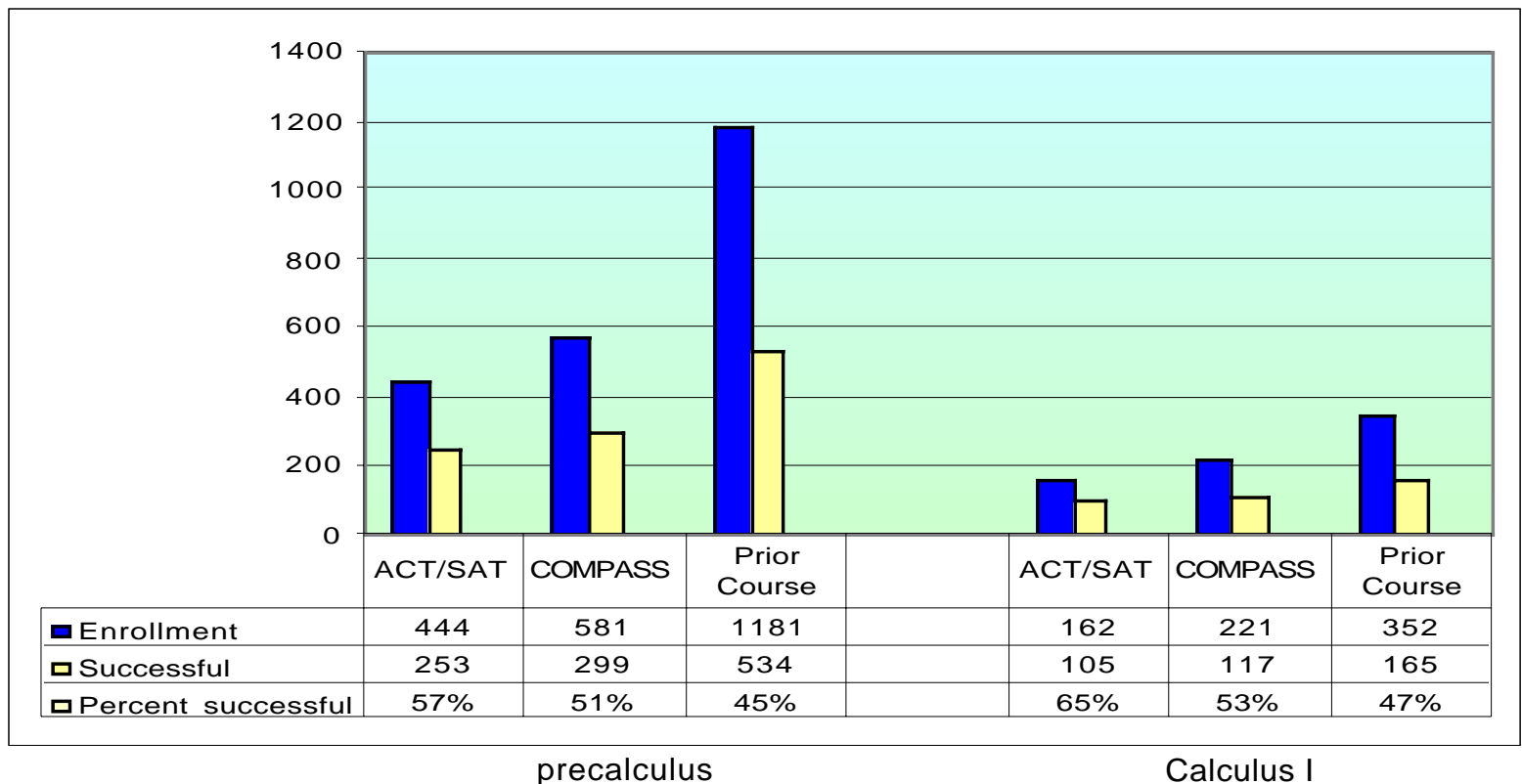

Data Source: Harper Institutional Research (2001).

\section{Summary}

The enrollment trends of the past twenty years provide us with a "reality check" on various assumptions. An analysis of enrollment data at four-year colleges and universities shows that:

- calculus enrollment are declining, both in actual numbers and as a percentage of the total undergraduate mathematics enrollment at the same time that mathematics enrollment overall is increasing.

- courses which have experienced the greatest growth during the past decade are the noncalculus based courses such as Elementary Statistics, Mathematics for Liberal Arts Students (Quantitative Literacy), and the Mathematics for Elementary Teachers.

- even though enrollment in the Precalculus/Elementary functions course are growing at a much faster rate, the vast majority of students take College Algebra.

- the increasing precalculus enrollment have had no impact on calculus enrollment.

- graphing calculators are now used in nearly $50 \%$ of sections teaching Calculus I but in less than one-third of the developmental algebra sections. 
The precalculus courses are filters which block many students from attaining their educational goals_-perhaps even more so than Calculus. Increasing numbers of these students pay college tuition for courses taken previously in high school which do not satisfy general education graduation requirements. These courses move along at a pace many students find impossible to maintain. Already over-taxed algebraic skills, combined with time constraints due to unrealistic commitments of full-time enrollment (12 semester hours) and 20 or more hours of outside employment per week on the part of many of these students doom them to yet another unsuccessful mathematical experience.

Many factors need to be taken into consideration when analysing the data presented in this paper. In order to interpret the data meaningfully, one should also examine student behaviors in the context of the classroom environment- taking into consideration the sequence and methods of instruction; the topics on which emphasis is placed; students' beliefs and attitudes; and the means by which conceptual knowledge and skill competencies are assessed.

The intended curriculum - the course content as outlined in the syllabus or based on the textbook, is not necessarily the implemented curriculum — what is actually taught. The number of sections in the text that students actually study, the sequence in which topics are studied, and the time spent investigating various topics significantly impact the formation of students' knowledge. Assessment choices-what is assessed, the methods and artifacts of assessment—place an emphasis on certain aspects of the curriculum at the expense of other parts of the curriculum.

Prior factors such as students' backgrounds, attitudes, cognitive preferences, and their mathematical competencies also need to be considered. Many students' prior experiences with mathematics have led them to believe that mathematics is a collection of meaningless rules and procedures to be memorized [DeMarois, P. \& McGowen, M., 1996; Keller \& Hirsch, 1994; McGowen, M. \& Davis, G., 2001; Tall, D., 1994; Tall, D. \& Razali, M.,1993, Thompson, P. 
1994]. Often, the focus has been on instruction that contributes to instrumental understanding"rules without reason" [Skemp, 1987].

Interviews with students and their mathematical autobiographies provide descriptions of their prior experiences-revealing deeply-entrenched beliefs about mathematics and what it means to learn mathematics. The following comments are typical:

"Coming into this class, I was under the impression that finding a formula to solve a problem was, in reality, the answer to the problem."

"All throughout school, we have been taught that mathematics is simply just plugging numbers into a learned equation. The teacher would just show us the equation dealing with what we were studying and we would complete the equation given different numbers because we were shown how to do it."

"When I began learning mathematics everything was so simple. As I got older there were many more rules taught to me. The more rules I learned, the easier it became to forget some of the older rules."

Responses of students majoring in mathematics reveal their inadequate understanding of mathematics as well. Recently, when asked to explain the difference between solving an equation and evaluating a function or expression, a graduate student who works as an on-line tutor replied:

"If a book asks you to evaluate $x^{2}-2 x+1$, what they are asking for is a simplified version of this polynomial which would be $(x-1)^{2}$. Solving an equation or expression is actually plugging in a particular value to come up with a solution.

For example:

$$
\begin{aligned}
& f(x)=x^{2}-2 x+1 . \text { Solve for } f(4) . \\
& f(4)=4^{2}-2(4)+1=16-8+1=9 .
\end{aligned}
$$

Is this helping you feel a little bit better about the difference between the two?"

Another factor which influences student understanding is the nature of the use of technology in the class. How instructors incorporate technology and how students use the technology are other factors that impact student learning and understanding of concepts. Incorporation of technology into a course changes the nature of the learning process-the sequence of instruction as 
well as the types of skills students need to learn. Students who are already having difficulties coping with learning new mathematical concepts and procedures tend to view the graphing calculator as a tool they reject-it necessitates the learning of more procedures, along with the mathematics they are already struggling to learn. These students elect not to add to their cognitive burdencontinuing to depend on rote-learned algorithms using pencil and paper as their primary tools. Contrast the learning experiences of two students in the same class:

"Another process that was very helpful in understanding algebra (specifically factoring) was using a graph to find the $x$-intercepts to find the zeros of an equation. This is a procedure I had never seen before, but I was able to connect it to my prior knowledge. I found the graphing calculator very useful to graph equations to find the number of solutions (finding zeros), and also to find equations when they are unknown (using the graphing calculator as a data process machine)." Student A.

"I find the graphing calculator to be very confusing. I feel as if everything is thrown at me at once. I have never used the graphing calculator before this class, and now I find it difficult to adopt to using it. The only thing I can do without too much difficulty is put a table into the calculator. After that I don't know what to do." Student B.

We also need to take into account the impact on college calculus enrollment of the increasing number of students who successfully complete Advanced Placement Calculus courses in high school. In 1999, 127,744 students took the Calculus AB exam and $64 \%$ of those who attempted the $\mathrm{AB}$ exam received a grade of 3 or better. Forty percent received a grade of 4 or 5 . The following year, 137,000 students took the $\mathrm{AB}$ exam, with $63 \%$ receiving a grade of 3 or better. This year, the number of students taking the AB Calculus Exam increased to 146,771 students. Again 63\% received a score of 3 or higher.

The number of students who took the AP BC exam also continues to increase. The number of students taking the BC exam increased from 30,724 students in 1999 to 34,142 students in 2000, with more than $75 \%$ of these students receiving a score of 3 or better. This year 38,134 students took the BC Calculus exam, with $67 \%$ of those students receiving a score of 3 or better [The College Entrance Examination Board, 2001.] What mathematics courses do these students take as 
undergraduates? If more and more students are taking Advanced Placement Calculus in high school, they are not taking precalculus or Calculus I in college. It is probable that many of the students enrolling in precalculus courses as undergraduates are students for whom learning mathematics has not been easy. If this is true, what are the implications for precalculus courses?

According to the 2000 U.S. Statistical Abstracts, more than one million bachelor's degrees $(1,164,792)$ were awarded in 1996 . One percent $(13,143)$ of those degrees were in mathematics. The number of associate degrees in mathematics was one-tenth of one percent of all associate degrees awarded that year (758 of 555,216). Based on the data from the CBMS 2000 Statistical Abstract (in preparation), mathematics enrollment in precalculus and calculus courses leading to a degree in mathematics has not improved during the past five years.

It is evident that much additional information is needed if we are to effect meaningful changes in the precalculus curriculum. The precalculus data, like the calculus enrollment data, generate more questions for which we do not have answers. We need answers to the questions:

- Who takes precalculus courses and for what reasons?

- How many students take precalculus to satisfy required prerequisites for a program of study other than mathematics?

- What do other programs of study expect students who complete precalculus to know?

- Are students who take the precalculus course(s) successful in subsequent courses?

- Why do more students continue to enroll in College Algebra than in all of other precalculus courses combined?

- Why has the Precalculus/Elementary functions course - a course designed for students intending to take Calculus-experienced such large increases in enrollment while Calculus I enrollment declined at four-year colleges and universities and remained relatively constant at two-year colleges since 1990?

Perhaps, more importantly, as we seek answers to these questions, we need to determine why we are attracting fewer and fewer students into our mathematics-intensive programs as the demand for individuals with strong mathematical competencies is increasing. 


\section{References}

College Entrance Examination Board, (2001) http://www.collegeboard.org/ap/calculus/html/ grade01.html, html/grade00.html, html/grade99.html.

DeMarois, P. \& McGowen, M. (1996) Understanding of Function Notation by College Students in a Reform Developmental Algebra Curriculum. Proceedings of the 18th Annual Meeting of the North American Chapter of the International Group for the Psychology of Mathematics Education., Panama City, Florida. Vol. 1, 183-186.

Douglas, R. G. (1986) Toward a Lean and Lively Calculus. Mathematical Association of America, MAA Notes No.6.

Keller, B. A. \& Hirsch, C. R. (1994) Student Preferences for Representations of Functions. In Lum, L. (Ed) Proceedings of the Fifth Annual International Conference on Technology in Collegiate Mathematics. Reading, Mass: Addison-Wesley Publishing Company. 178-190.

Loftsgaarden, D. O., Rung, D. C. and Watkins, A. E. (1997) Statistical Abstract of Undergraduate Programs in the Mathematical Sciences in the United States: Fall 1995 CBMS Survey. Mathematical Association of America, MAA Reports No.2.

Lutzer, D. (in press) Statistical Abstract of Undergraduate Programs in the Mathematical Sciences in the United States: Fall 2000 CBMS Survey. Mathematical Association of America.

McGowen, M. and Davis, G. (2001) Changing Pre-Service Elementary Teachers' Attitudes to Algebra. In Chick, H., Stacey, K., Vincent, J. \& Vincent, J (Eds.) Proceedings of the 12th ICMI Study on The Future of the Teaching and Learning of Algebra. University of Melbourne, Australia: Vol. 2, 438-335.

McGowen, M.and Tall, D. (1999) Concept maps and schematic diagrams as devices for documenting the growth of mathematical knowledge. In O.Zaslavsky (Ed.). Proceedings of the 23rd International Group for the Psychology of Mathematics Education. Haifa, Israel. Vol. 3, 281-288.

National Center for Education Statistics (NCES) (1997) Findings From Education and the Economy: An Indicators Report, Washington, DC: U.S. Government Printing Office, http:// nces.ed.gov/pubs97/97939.html.

Skemp, R. (1987) The Psychology of Learning Mathematics Expanded American Edition. Hillsdale, NJ: Lawrence Erlbaum \& Associates, Publishers.

Tall, D. (1994) Understanding the Processes of Advanced Mathematical Thinking. An Invited ICMI presentation at the International Congress of Mathematicians. Zurich. Available online at: http://www.davidtall.com.

Tall, D.O. and Razali, M. R. (1993) Diagnosing Students' Difficulties in Learning Mathematics. International Journal for Math, Education, Science \& Technology 24 (2). 202-209.

Thompson, P. (1994) Students, Functions, and the Undergraduate Curriculum. In Dubinsky, E., Schoenfeld A. and Kaput, J. J., (Eds.). Research in Collegiate Mathematics Education, I. CBMS Issues in Mathematics Education. Vol. 4. 21-44.

U.S. Department of Labor, Bureau of Labor Statistics.(1997) Occupational Outlook Handbook, Washington, DC: U.S. Government Printing Office, http://stats.bls.gov:80/oco2003.htm. 